\title{
Prediagnosis lifestyle exposures and survival of gastric cancer patients: a cohort study from Portugal
}

\author{
I Ferronha', C Castro' ${ }^{2}$, H Carreira' ${ }^{\text {I,4 }}$, MJ Bento ${ }^{2}$, I Carvalho ${ }^{3}$, B Peleteiro ${ }^{1,4}$ and N Lunet ${ }^{*, 1,4}$ \\ IInstitute of Public Health, University of Porto (ISPUP), Porto, Portugal; ${ }^{2}$ North Region Cancer Registry, Portuguese Oncology Institute, Porto, Portugal; \\ ${ }^{3}$ Cancer Registry of the S. João Hospital Center, Porto, Portugal; ${ }^{4}$ Department of Clinical Epidemiology, Predictive Medicine and Public Health, University of \\ Porto Medical School, Alameda Prof. Hernâni Monteiro, Porto, Portugal
}

\begin{abstract}
BACKGROUND: Dietary habits and smoking are recognised as important gastric cancer determinants. However, their impact on prognosis remains poorly understood. We aimed to quantify the association between lifestyles and survival of gastric cancer patients. METHODS: In 200I-2006, 568 patients were recruited in the two major public hospitals in the north of Portugal. Participants were inquired about smoking and dietary habits regarding the year preceding the diagnosis. The vital status of all participants, up to $201 \mathrm{I}$ (maximum follow-up: 10 years), was assessed through the North Region Cancer Registry. Cox proportional hazards regression models were used to estimate adjusted (at least for age, sex and education) hazard ratios (HR) and 95\% confidence intervals ( $95 \% \mathrm{Cl}$ ). RESULTS: No significant differences in gastric cancer survival were observed according to smoking status (current vs never smokers, $\mathrm{HR}=1.00,95 \% \mathrm{Cl}: 0.72-1.38$ ) or alcohol intake (current vs never consumers, $\mathrm{HR}=0.87,95 \% \mathrm{Cl}: 0.6 \mathrm{I}-1.25$ ). Only a dietary pattern (high consumptions of most food groups and low vegetable soup intake) was significantly associated with a better prognosis among patients with the extent of disease classified as regional spread ( $\mathrm{HR}=0.45,95 \% \mathrm{Cl}: 0.22-0.93)$.

CONCLUSION: This study shows that prediagnosis lifestyles have a small impact in the survival of gastric cancer patients. British Journal of Cancer (2012) I 07, 537-543. doi:I0.1038/bjc.20 I2.258 www.bjcancer.com

Published online 14 June 2012

(c) 2012 Cancer Research UK
\end{abstract}

Keywords: stomach neoplasms; survival; smoking; alcohol drinking; diet

Gastric cancer is the fourth most common malignancy in the world (Ferlay et al, 2010). Although its frequency has been declining for decades it remains the second leading cause of cancer mortality (Boyle and Levin, 2008) and ranks second among the cancers accounting for the highest number of disability-adjusted life years (9.6\%) (John and Ross, 2010; American Cancer Society, 2011). In Europe, the average 5-year relative survival rate of patients diagnosed between 2000 and 2002 was estimated in 24.9\%, however varying widely across countries (Verdecchia et al, 2007). In Portugal, gastric cancer ranks 5th in incidence and 3rd in mortality (Ferlay et al, 2010), despite the mortality rates are declining since the 1970s (Lunet et al, 2004). The rates are among the highest in Europe (Ferlay et al, 2010) and there is a large variation within the country, with incidence and mortality being much higher in the North (International Agency for Research on Cancer and International Association of Cancer Registries, 2007; Lunet, 2011). The 5 -year relative survival ranged between $28 \%$ for patients diagnosed in 2004 in the South (ROR-Sul, 2010) and 34\% for patients diagnosed in 2000/2001 in the North (RORENO, 2010).

The prognosis of gastric cancer patients varies with the tumour's characteristics, namely location and histological type, and it is also likely to be related with the socioeconomic status of the patients (Bouvier et al, 2010). The latter, in addition to its relation with access to health care and stage at diagnosis (Hamilton and

*Correspondence: Dr N Lunet; E-mail: nlunet@med.up.pt

Received 23 January 2012; revised 8 May 2012; accepted 10 May 2012; published online 14 June 2012
Aaltonen, 2000), may also be associated with environmental exposures with potential impact both in the risk of gastric cancer and in the survival of cancer patients. The understanding of the relation between prediagnosis lifestyles and survival may contribute to a more accurate characterisation of the burden associated with the established risk factors for gastric cancer, namely smoking (Lunet et al, 2005; Ladeiras-Lopes et al, 2008), high salt intake (World Cancer Research Fund and American Institute for Cancer Research), high consumption of red/processed meat (World Cancer Research Fund and American Institute for Cancer Research) or low fruit and vegetables intake (Lunet et al, 2005). Alcohol consumption does not seem to have an important role in gastric cancer aetiology, but has been associated with a poorer survival (Ferronha et al, 2012).

Therefore, we aimed to quantify the association between prediagnosis lifestyles and the survival of gastric cancer patients, in a large sample followed prospectively for up to 10 years, with special emphasis on the potential modification of the effects by clinical characteristics associated with prognosis.

\section{MATERIALS AND METHODS}

\section{Setting and selection of participants}

As part of a case-control study previously described in detail (Lunet et al, 2006, 2007; Peleteiro et al, 2011) we evaluated incident cases of gastric cancer selected among those admitted to the surgery wards of the two major public hospitals caring for cancer patients in the north of Portugal (Hospital de S. João and Instituto 
Português de Oncologia Francisco Gentil, both in Porto), between June 2001 and December 2006.

Eligible patients were incident gastric cancer cases that had not been previously diagnosed with cancer (except skin non-melanoma), nor had been subjected to subtotal gastrectomy for benign conditions; they also had to be able to provide informed consent. To evaluate cognitive function, all individuals older than 64 years took a Mini-Mental State Examination (Folstein et al, 1975) and we restricted the analysis to participants without serious cognitive impairment at baseline (score $\geqslant 18$ points) (Murden et al, 1991).

\section{Evaluation of environmental exposures}

The participants completed a comprehensive structured questionnaire providing information on demographic, social, behavioural and medical characteristics, applied by trained interviewers during in-hospital stay, shortly after admission, mostly before surgical treatment. As illness duration is related with changes in food intake, the assessment of the dietary intake referred to the previous year or the year before onset of symptoms, as applicable. We excluded from the analyses the patients declaring to have changed dietary habits more than 1 year before the interview.

Dietary exposures were quantified using a semi-quantitative food frequency questionnaire (FFQ) comprising $82 \mathrm{food} /$ beverage items or categories, designed according to Willett (1998) and adapted by inclusion of a variety of typical Portuguese food items. Foods with a similar nutrient composition were grouped together as a single item. The FFQ was validated with four 7-day food records and, regarding the fatty acid composition, with the composition of subcutaneous adipose tissue (Lopes, 2000; Lopes et al, 2007). The Spearman correlation coefficients were $0.36,0.73$ and 0.70 for protein, carbohydrates and total fat, respectively, and $0.49,0.43$ and 0.55 for beta-carotene, vitamin $\mathrm{E}$ and vitamin $\mathrm{C}$, respectively (Lopes, 2000). The correlation coefficients between the intake estimated using the FFQ and the composition of subcutaneous adipose tissue ranged from 0.44 for myristic acid $(14: 0)$ to -0.3 for $\alpha$-linolenic acid $(18: 3 ; n-3)$ (Lopes et al, 2007).

For each FFQ item, subjects were asked the average frequency of consumption (nine possible responses ranging from never to six or more times per day), the portion size usually consumed (based on a photograph manual with small, medium and large portion sizes) and the number of months during which it had been consumed in the previous year. Also, for each item, this information was used to estimate the frequency of consumption of medium servings, corrected for seasonality by multiplying the reported consumption by the ratio between the number of months during which the food item was reported to be consumed and 12 months. For analysis, the frequency of consumption of each food group was categorised using the tertiles of the overall distribution as cutoffs.

The overall intake of fruits and vegetables, red and processed meat and foods with a high contribution to salt intake was established by adding up the amounts of single items or groups consumed per day, as follows: fruits and vegetables (apple or pear, orange or mandarin, banana, kiwi, strawberry, cherry, peach or plum, melon or watermelon, persimmon, fig or loquat or apricot, grapes, natural fruit juices, lettuce, watercress, tomato, cucumber, green and white cabbages, broccoli, cauliflower or Brussels sprout, spinach or spring greens or turnip greens, spinach, bean pod, carrot, turnip, green beans, green pepper, onion, beans and peas); red and processed meat (beef, pork, liver, tongue, ham, sausage, bacon, hamburger); food items with the highest contribution to sodium intake (grains, cereals, rice, pasta, potatoes, bread, meat, meat products, offal, vegetable soup, fish and cheese). The latter were defined according to the results of a previous nutrition survey conducted in same setting (Lopes et al, 2006).

Dietary patterns were defined by principal components and cluster analyses, as previously described in detail (Bastos et al, 2010). Three dietary patterns were identified (Pattern I - high consumption of dairy products, fruits, salads and vegetables, and low consumption of meat and alcoholic beverages; Pattern II - low consumption of most food groups, specifically dairy products, fish and seafood, fruit, salads, vegetables and meat; Pattern III - high consumptions of most food groups and the lowest vegetable soup intake). Pattern II was shown previously to be associated with a higher risk of gastric cancer when compared with patterns I or III (Bastos et al, 2010).

Smoking and alcohol consumption status were assessed. Individuals smoking at least one cigarette per day were classified as current smokers and those who stopped smoking at least 6 months before the interview as former smokers (World Health Organization, 1999). For current smokers, the lifetime consumption in pack-years was computed by multiplying the number of years that each subject has smoked by the average daily tobacco consumption expressed in number of packs ( 1 pack $=20$ cigarettes). Individuals drinking at least one alcoholic drink per day were classified as current drinkers and those who stopped drinking at least 6 months before the interview as former drinkers. Current drinkers were further divided according to type of alcoholic drink and amount of ethanol consumed (American Heart Association Nutrition Committee et al, 2006).

\section{Clinical characteristics}

The anatomic site (cardia, proximal, middle, distal or not defined) and histological type of the tumours (intestinal, diffused or mixed) were classified according to the routine procedures of both institutions, based on gastrectomy specimens or endoscopic biopsy material. To guarantee a standard pathologic classification according to the Laurén criteria, a single experienced pathologist reviewed all pathology reports and slides were reassessed whenever necessary. For a more accurate classification of the tumour histological type (Palli et al, 1991; Flucke et al, 2002) only those cases from whom a surgical specimen was available were considered for the analyses including information on the tumours' histological type (78\% of the patients eligible for data analysis).

The information on the extent of disease, according to the European Network of Cancer Registries criteria (Berrino et al, 2002), was obtained from the North Region Cancer Registry (RORENO).

\section{Follow-up}

The vital status of the participants was assessed by the RORENO. The event of interest was death by all causes. Patients were followed until the end of July, 2011, or date of death, whichever occurred first. No follow-up information could be obtained for 10 patients. The median duration of follow-up was 6.6 years for patients alive at the end of study and 1.2 years for those reported dead, with a maximum follow-up of 10 years.

\section{Statistical analysis}

A total of 568 gastric cancer patients with follow-up information were available for data analysis. We used the Kaplan-Meier survival function to estimate the observed survival at 1,3 and 5 years of follow-up. Differences in survival estimates between groups were tested using the Log-rank test. Cox proportional hazard regression analysis was used to compute hazard ratios (HR), both crude and adjusted for age, sex, education, total energy intake and extent of disease, with the corresponding $95 \%$ confidence intervals ( $95 \% \mathrm{CI}$ ). This core of variables strongly associated with lifestyle exposures and with the prognosis of the gastric cancer patients is expected to account for most of the confounding. We also tested models including smoking, drinking of alcoholic beverages and Helicobacter pylori infection. These variables did not influence the estimates meaningfully and we 
opted for providing the HR estimates obtained from the more parsimonious models. We also conducted stratified analyses according to three clinical variables strongly associated with the prognosis of these patients (topography, histological type and extent of disease). The proportional hazards assumption was evaluated graphically using 'log-log' plots.

All analyses were conducted using STATA, version 11.2 (StataCorp., College Station, TX, USA).

\section{Ethics}

The study was approved by the ethics committees of the involved hospitals and the participants provided written informed consent.

\section{RESULTS}

\section{Characteristics of the participants}

Incident gastric cancer patients were mostly men $(62.1 \%)$ and nearly one-quarter were aged 50 years or less (median age of 63 years). Approximately three-quarters of the participants had 4 or less schooling years. Most cancers were located in the non-cardia region $(78.6 \%)$, and $55 \%$ of those from whom a surgical specimen was available were of the Laurén's intestinal histological type. No information was available to classify $16.9 \%$ of the cases according to the extent of disease, and one-quarter were advanced cancers (Table 1).

At baseline, approximately one-quarter of the patients were exsmokers and one-fifth were current smokers. Approximately threequarters of the patients were current drinkers, $30.5 \%$ reported wine as the only alcoholic beverage consumed and $43.1 \%$ had a daily intake above the recommendations. The median daily consumption of fruits and vegetables, red and processed meat and foods accounting for high salt intake was 3.4, 0.7 and 7.7 servings, respectively (Table 2 ).

\section{Survival analysis}

Survival was lower among women $(35.8 \%$ vs $44.2 \%$ at 5 years, $P=0.016)$, and decreased significantly with age $(P=0.001)$ and education $(P=0.027)$. Cardia cancers and those of the Laurén's diffuse type had a significantly lower survival. Only $32.4 \%$ and $7.0 \%$ of the patients with an advanced cancer were alive at 1 and 3 years after diagnosis, respectively (Table 1).

Regarding the relation with lifestyle characteristics, significant differences were observed only for ex-smokers compared with never smokers $(\mathrm{HR}=0.72,95 \% \mathrm{CI}$ : 0.55-0.94), although no significant differences were observed after adjustment for potential confounders (Table 2). An increased hazard rate, though not statistically significant, was observed among the patients with localised/local spread cancer for smoking status when comparing current $v s$ never smokers $(\mathrm{HR}=2.17,95 \%$ CI: 0.51-9.22), especially among smokers reporting a lifetime exposure $<20$ pack-years $(\mathrm{HR}=4.71,95 \% \mathrm{CI}$ : 0.45-48.97) (Table 3 ).

Regarding dietary exposures, a significantly lower hazard rate was observed only among regional spread patients with dietary pattern III (high consumptions of most food groups and lowest vegetable soup intake), compared with those with pattern I (high consumption of dairy products, fruits, salads and vegetables, and low consumption of meat and alcoholic beverages) ( $\mathrm{HR}=0.45$, 95\% CI: 0.22-0.93); a similar non statistical significant relation was observed among those with localised/local spread patients (Table 3). The higher HR point estimates were observed among the patients with localised/local spread cancer for the consumption of higher amounts of fruits and vegetables (3rd third $v s$ 1st third, $\mathrm{HR}=2.52$; $95 \% \mathrm{CI}: 0.84-7.60$ ), red and processed meat (3rd third vs 1 st third, $\mathrm{HR}=2.43 ; 95 \% \mathrm{CI}: 0.73-8.10)$ and foods accounting
Table I Observed survival of gastric cancer patients at 1, 3 and 5 years according to socio-demographic and clinical characteristics

\begin{tabular}{|c|c|c|c|c|c|c|}
\hline & \multirow[b]{2}{*}{$n(\%)$} & \multirow{2}{*}{$\begin{array}{c}\text { Deaths } \\
\text { during } \\
\text { follow-up } \\
\text { (n) }\end{array}$} & \multicolumn{4}{|c|}{ Observed survival (\%) } \\
\hline & & & $\begin{array}{c}\text { I } \\
\text { Year }\end{array}$ & $\begin{array}{c}3 \\
\text { Years }\end{array}$ & $\begin{array}{c}5 \\
\text { Years }\end{array}$ & $\begin{array}{c}P \\
\text { value }\end{array}$ \\
\hline \multicolumn{6}{|l|}{ Sex } & 0.016 \\
\hline Women & $215(37.9)$ & 142 & 65.6 & 43.3 & 35.8 & \\
\hline Men & $353(62.1)$ & 203 & 75.9 & 52.7 & 44.2 & \\
\hline \multicolumn{6}{|l|}{ Age (years) } & 0.001 \\
\hline$\leqslant 50$ & $13 \mid(23.1)$ & 65 & 79.4 & 57.3 & 51.9 & \\
\hline $51-60$ & $120(21.1)$ & 66 & 78.3 & 56.7 & 45.0 & \\
\hline $61-70$ & $156(27.5)$ & 98 & 66.0 & 44.2 & 38.5 & \\
\hline $71-80$ & $129(22.7)$ & 92 & 66.7 & 39.5 & 31.0 & \\
\hline$\geqslant 81$ & $32(5.6)$ & 24 & 68.8 & 50.0 & 34.4 & \\
\hline \multicolumn{6}{|l|}{ Education (years) } & 0.027 \\
\hline 0 & $65(11.4)$ & 46 & 60.0 & 40.0 & 33.9 & \\
\hline $\mid-3$ & $98(17.3)$ & 67 & 62.2 & 40.8 & 33.7 & \\
\hline 4 & $282(49.6)$ & 161 & 76.2 & 51.4 & 44.3 & \\
\hline $5-9$ & 89 (I5.7) & 49 & 78.7 & 59.6 & 46.0 & \\
\hline$\geqslant 10$ & $34(6.0)$ & 22 & 70.6 & 44.1 & 35.3 & \\
\hline \multicolumn{6}{|l|}{ Anatomic site } & $<0.001$ \\
\hline Cardia & $69(12.2)$ & 51 & 62.3 & 37.7 & 29.0 & \\
\hline $\begin{array}{l}\text { Proximal } \\
\text { one-third/fundus }\end{array}$ & $12(2.1)$ & 6 & 75.0 & 66.7 & 58.3 & \\
\hline $\begin{array}{l}\text { Middle } \\
\text { one-third/body }\end{array}$ & $61(10.7)$ & 36 & 68.8 & 45.9 & 44.3 & \\
\hline $\begin{array}{l}\text { Distal one-third/ } \\
\text { antrum-pylorus }\end{array}$ & $374(65.8)$ & 206 & 80.8 & 56.4 & 46.2 & \\
\hline Not-classified & $52(9.2)$ & 46 & 25.0 & 11.5 & 11.5 & \\
\hline \multicolumn{6}{|l|}{ Histological type $\mathrm{e}^{\mathrm{a}}$} & 0.001 \\
\hline Intestinal & $244(55.0)$ & 113 & 86.5 & 65.2 & 56.6 & \\
\hline Diffuse & $127(28.6)$ & 82 & 78.0 & 47.2 & 36.2 & \\
\hline Mixed & $73(16.4)$ & 42 & 78.1 & 52.1 & 43.8 & \\
\hline \multicolumn{6}{|l|}{ Extent of disease } & $<0.00$ \\
\hline Localised & $112(19.7)$ & 11 & 96.4 & 92.7 & 91.1 & \\
\hline Local spread & $37(6.5)$ & II & 97.3 & 81.1 & 73.0 & \\
\hline Regional spread & $|8|(31.9)$ & 121 & 86.2 & 54.7 & 36.4 & \\
\hline Advanced & $142(25.0)$ & 137 & 32.4 & 7.0 & 4.9 & \\
\hline Unknown & $96(16.9)$ & 65 & 66.6 & 37.5 & 32.3 & \\
\hline
\end{tabular}

a This information is available from 444 patients that underwent surgical resection of the stomach.

for high salt intake (3rd third $v s$ st third, $\mathrm{HR}=2.18$; 95\% CI: 0.59-8.03) (Table 3).

No independent statistical significant associations were observed between the alcohol intake (defined according to status, type of alcoholic drink or amount of ethanol consumed per day) and gastric cancer survival, overall or across strata defined by cancer subsite, histological type or stage (Tables 2 and 3 ). However, despite the lack of statistical significance the results suggest a negative association among the drinkers, consistent across the different criteria to define exposure and regardless of the level or nature of the exposure (Table 3 ).

There were virtually no changes in the results when excluding the patients who died up to 15 days after the surgery, when applicable, more likely to be due to postoperative complications (data not shown).

\section{DISCUSSION}

The present study shows no significant associations between prediagnosis lifestyles and gastric cancer survival, with the 
Table 2 Observed survival of gastric cancer patients at I, 3 and 5 years, and respective hazard ratios, according to lifestyle characteristics

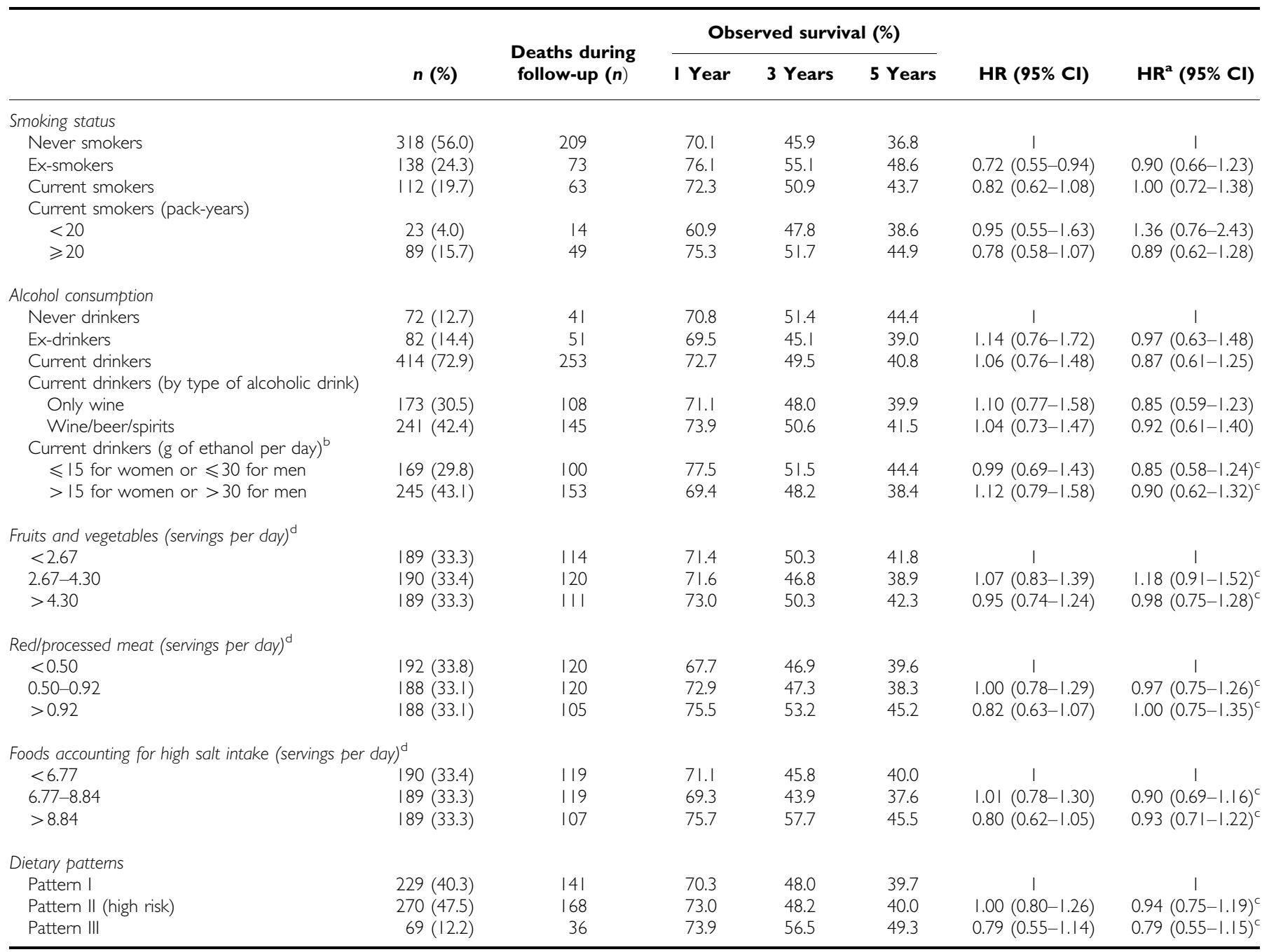

Abbreviations: $\mathrm{Cl}=$ confidence intervals; $\mathrm{HR}=$ hazard ratios. ${ }^{2}$ Adjusted for age, sex, education (continuous), extent of disease (grouped in localised and local spread; regional spread; advanced; unknown). ${ }^{b}$ According to the recommendations for each sex (American Heart Association Nutrition Committee et al, 2006). 'Additionally adjusted for total energy intake. ${ }^{d}$ The tertiles of the distribution in all participants were used as cut-offs.

exception of a lower hazard rate among patients with less advanced disease reporting a dietary pattern also associated with a lower risk of gastric cancer.

This is one of the few investigations (Ferronha et al, 2012) on the association between prediagnosis behaviours and gastric cancer survival. Nonetheless, this study has three main limitations that need to be addressed.

As no information on the cause of death was available, the endpoint was all-cause mortality. Therefore, the factors that we identified as being associated with the hazard rates are not necessarily influencing the risk of death specifically due to gastric cancer. However, all-cause mortality may be a good surrogate of gastric cancer mortality due to the low overall survival of gastric cancer patients, despite this is less likely among the subjects presenting with less advanced disease.

Recall bias may have occurred, as cases may provide a less accurate report of their past dietary habits, because unnoticed changes in intake may occur as cancer develops and becomes symptomatic (Botterweck et al, 1998). In our study, we partially overcame these constraints to data interpretation by electing incident cases, and referring information to the year before diagnosis or to the period immediately before any changes in dietary habits. In addition, quality of reporting was improved by excluding patients with an abnormal score in the Mini-Mental
State Examination, and participants who reported changes in their diet more than 1 year before interview. Nevertheless, the lower HR observed among patients with a dietary pattern of high consumption of most food groups or with higher consumption of alcoholic beverages may reflect the better general condition of these patients before diagnosis, which is in accordance with the fact that this was only observed in those with less advanced disease. On the other hand, the higher HR observed among the patients in the earlier stages for the higher consumptions of fruit and vegetables, $\mathrm{red} /$ processed meat or foods accounting for high salt intake may also reflect a differential reporting of specific dietary intakes according to the phases of disease development, that was not captured by the more comprehensive assessment of dietary exposure allowed by the food patterns analysis.

The small number of cases in some strata of different subgroup analysis contributes to a limited statistical power, namely taking into account that the associations observed were generally weak. Nevertheless, this is one of the largest studies on this topic conducted so far (Ferronha et al, 2012), and the stratified analyses provide new insights on the relation between prediagnosis lifestyles and the survival of gastric cancer patients that overcome the sample size limitations. It should also be taken into account that the results were generally consistent, despite the imprecision of some of the HR estimates. 
Table 3 Adjusted hazard ratios and corresponding 95\% confidence intervals for lifestyle characteristics using multivariate Cox regression model

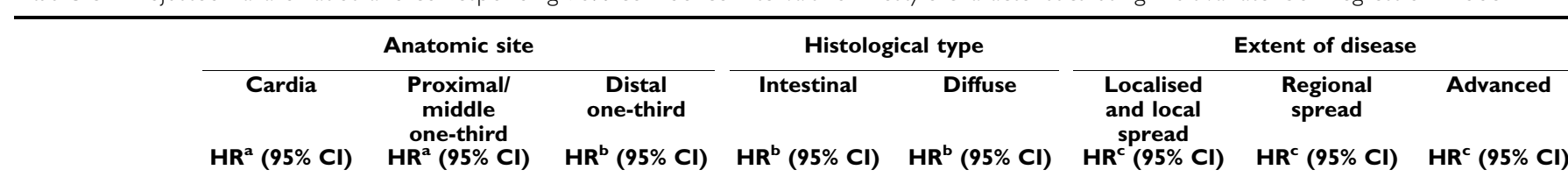

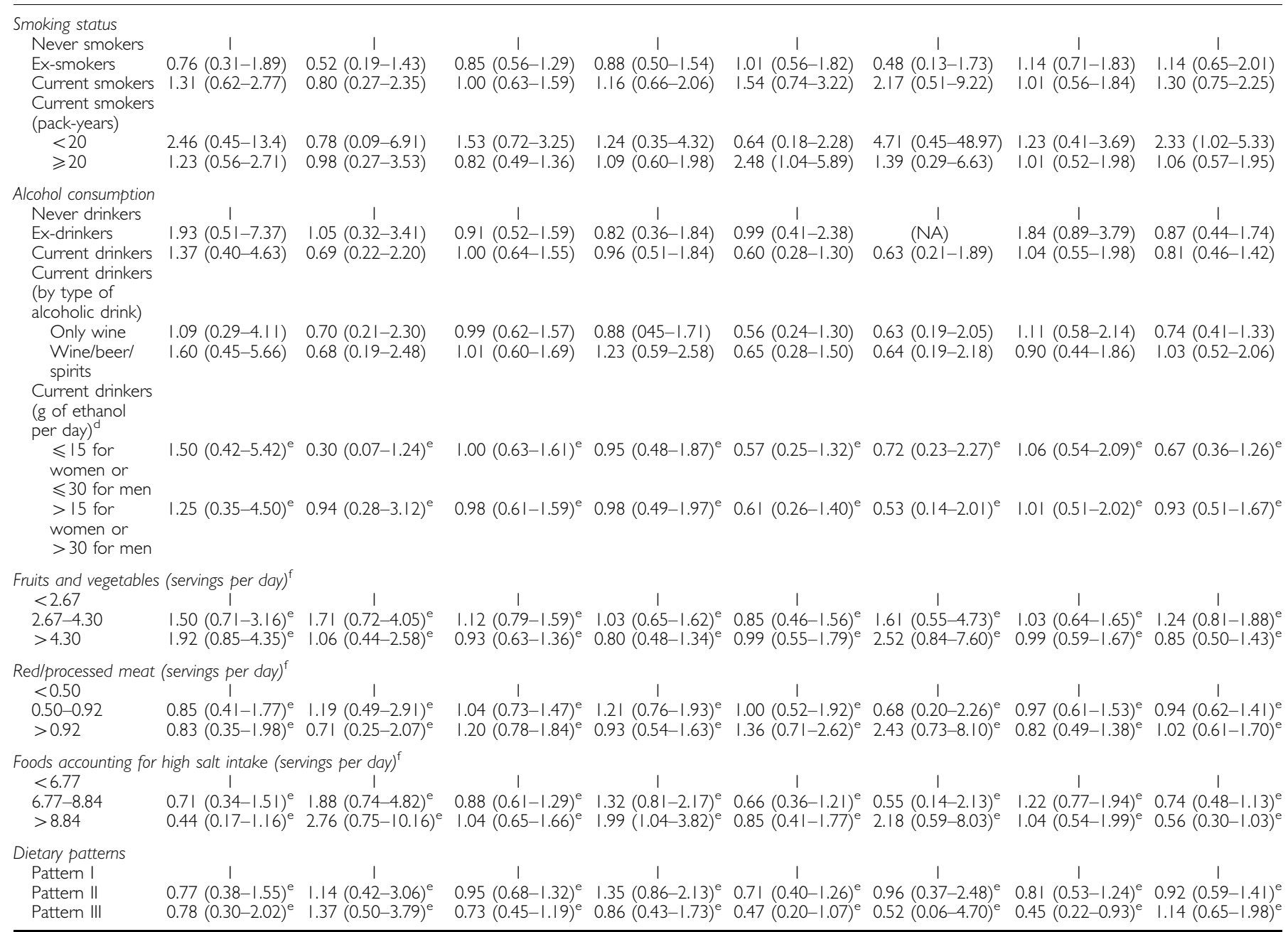

Abbreviations: $\mathrm{Cl}=$ confidence intervals; $\mathrm{HR}=$ hazard ratios; $\mathrm{NA}=$ not applicable (there are no ex-drinkers patients with an extent of disease as localised and/or local spread). ${ }^{a}$ Adjusted for age (continuous), sex, education (continuous), extent of disease (grouped in localised, local spread and regional spread; advanced; unknown). ${ }^{\mathrm{b}}$ Adjusted for age (continuous), sex, education (continuous), extent of disease (grouped in localised and local spread; regional spread; advanced; unknown). ' $A d j$ justed for age (continuous), sex, education (continuous). ${ }^{\mathrm{d} A c c o r d i n g}$ to the recommendations for each sex (American Heart Association Nutrition Committee et al, 2006). ${ }^{\mathrm{e}}$ Additionally adjusted for total energy intake. ${ }^{f}$ The tertiles of the distribution in all participants were used as cutoffs.

Previous investigations showed that cancer patients may adopt healthier lifestyles after diagnosis or treatment (Blanchard et al, 2003; Patterson et al, 2003; Pacheco-Figueiredo et al, 2011). Subjects with less healthy eating patterns before diagnosis may be more prone to change comparing with those who already had a more healthy diet. This could contribute for differences in survival according to lifestyle changes after gastric cancer diagnosis, but these were not assessed in our study, and their potential confounding effect could not be accounted. Nonetheless, the HR estimates computed in our study were adjusted for the most important confounders, contributing to the validity of the estimates. In our analyses, the potential confounding by socioeconomic status was taken into account essentially through the education level of the participants. Although socioeconomic status may be associated with survival owing to a differential access to health-care services, residual confounding is unlikely to have an important role in this study. In Portugal, the National Health
Service guarantees universal access to the population, which may contribute to attenuate differences in survival across the levels of socioeconomic status. Moreover, the participants in our study were recruited from the two largest public hospitals caring for oncological patients in the North region, and therefore we expect homogeneity in their management. Another potential confounder of the associations investigated in this study is $H$. pylori infection, which was assessed in a subsample of subjects who agreed to provide a blood sample $(n=431)$, as previously described in detail (Peleteiro et al, 2010). In this subsample, the conclusions were similar to the ones obtained when considering all the participants; the results remained unchanged after further adjustment for infection status or infection with $\mathrm{CagA}^{+}$strains.

There are several distinctive methodological characteristics of the present investigation that contribute to the robustness and validity of the findings. It is based on a large case series of patients followed for a long period, which allows a stratified analysis 
according to the extent of disease, and consequently the estimation of the impact of these exposures specifically for subgroups of patients with short and long survival periods. This strategy of analysis has not been used in the previous studies, although we may hypothesise that lifestyles adopted for several years before diagnosis are unlikely to be responsible for the differences in mortality of gastric cancer patients shortly after the disease diagnosis.

In a recent meta-analysis (Ferronha et al, 2012) we showed that smoking and alcohol drinking were the behavioural exposures more often studied. Current drinkers had higher HR (summary $\mathrm{HR}=1.13$, 95\% CI: 1.00-1.28) compared with those who were never drinkers. We did not found a consistent increased risk for current drinkers compared with the never drinkers. However, the magnitude of the differences are small and our results cannot be interpreted as meaningfully different from those already reported, namely considering the imprecision of the estimates. Furthermore, also adds to previous research the assessment of the effect of specific types of alcoholic drinks.

Regarding smoking, the corresponding results of the metaanalysis were less consistent ( $\mathrm{HR}=1.08,95 \% \mathrm{CI}: 0.90-1.30)$ and compatible with those reported in our study. We also studied the effect of smoking more thoroughly, providing information on survival by anatomic site, histology and tumour stage, which could have special interest for clinical purposes. These stratified analyses suggest an increased risk of death for the patients smoking up to 20 pack-years with cardia or less advanced cancers, and for smokers of more than 20 pack-years with the diffuse form of the disease.

Only two previous reports addressed the effect of dietary exposures on the survival of gastric cancer patients (Huang et al, 2000; Palli et al, 2000), and our investigation provides new evidence on these potential determinants of prognosis. In addition to using valid methods to assess dietary intake before cancer diagnosis or symptoms, we analysed the potential effect of the exposure to food groups known to be associated with the risk of gastric cancer, as well as the effect of dietary patterns. The latter provides an additional tool to understand the impact of diet in cancer survival.

The specificity of some of the exposures addressed in our study, namely the amounts of different food items consumed or, more importantly, the overall dietary pattern, which is clearly localespecific, may limit the external validity of our study. However, we expect a similar effect of the prediagnosis lifestyles across settings, and our results may apply to other populations. Nonetheless, for the comparisons to be meaningful, the levels of exposure and study design and data analysis, especially the validity of the exposure assessment and control of confounding, need to be taken into account. Our results may contribute for a better understanding of the role of lifestyles on the overall burden of gastric cancer, but can hardly be used to support public health messages to the population, as they could be more useful in a clinical setting than for primary prevention.

In conclusion, our study provides robust evidence that prediagnosis lifestyles have a small impact in the survival of gastric cancer patients, and provides a benchmark for further research on the effect of dietary exposures.

\section{ACKNOWLEDGEMENTS}

Grants from Fundação para a Ciência e Tecnologia are gratefully acknowledged (PTDC/SAU-ESA/71517/2006, POCI/SAU-ESP/56126/ 2004, POCI/SAU-ESP/61685/2004).

\section{REFERENCES}

American Cancer Society (2011) Global Cancer Facts \& Figures. 2nd edn. American Cancer Society: Atlanta, Georgia

American Heart Association Nutrition Committee, Lichtenstein $\mathrm{AH}$, Appel LJ, Brands M, Carnethon M, Daniels S, Franch HA, Franklin B, Kris-Etherton P, Harris WS, Howard B, Karanja N, Lefevre M, Rudel L, Sacks F, Van Horn L, Winston M, Wylie-Rosett J (2006) Diet and lifestyle recommendations revision 2006: a scientific statement from the American Heart Association Nutrition Committee. Circulation 114(1): 82-96

Bastos J, Lunet N, Peleteiro B, Lopes C, Barros H (2010) Dietary patterns and gastric cancer in a Portuguese urban population. Int J Cancer 127(2): 433-441

Berrino F, Brown C, Möller T, Sobin L, Faivre J (2002) ENCR Recomendations Condensed TNM for Coding the Extent of Disease. European Network of Cancer Registries: Lyon, France

Blanchard CM, Denniston MM, Baker F, Ainsworth SR, Courneya KS, Hann DM, Gesme DH, Reding D, Flynn T, Kennedy JS (2003) Do adults change their lifestyle behaviors after a cancer diagnosis? Am J Health Behav 27(3): 246-256

Botterweck AA, van den Brandt PA, Goldbohm RA (1998) A prospective cohort study on vegetable and fruit consumption and stomach cance risk in The Netherlands. Am J Epidemiol 148(9): 842-853

Bouvier AM, Sant M, Verdecchia A, Forman D, Damhuis R, Willem Coebergh J, Crocetti E, Crosignani P, Gafa L, Launoy G, MartinezGarcia C, Plesko I, Pompe-Kirn V, Rachtan J, Velten M, Vercelli M, Zwierko M, Esteve J, Faivre J (2010) What reasons lie behind long-term survival differences for gastric cancer within Europe? Eur J Cancer 46(6): 1086-1092

Boyle P, Levin B (2008) World Cancer Report 2008. International Agency for Research on Cancer (IARC): Lyon, France

Curado MP, Edwards B, Shin HR, Storm H, Ferlay J, Heanue M, Boyle P (2007) Cancer Incidence in Five Continents Vol. IX, IARC Scientific Publications No. 160, IARC: Lyon

Ferlay J, Shin H, Bray F, Forman D, Mathers C, Parkin D (2010) GLOBOCAN 2008 v1.2, Cancer Incidence and Mortality Worldwide: IARC CancerBase No. 10 [Internet]. Lyon, France: International Agency for Research on Cancer; 2010. Available from: http://globocan.iarc.fr (accessed on 20/12/2012)

Ferronha I, Bastos A, Lunet N (2012) Pre-diagnosis lifestyle exposures and survival of gastric cancer patients: systematic review and meta-analysis. Eur J Cancer Prev; e-pub ahead of print 8 April 2012; doi:10.1097/ CEJ.0b013e32834fdb1b

Flucke U, Monig SP, Baldus SE, Zirbes TK, Bollschweiler E, Thiele J, Dienes HP, Holscher AH (2002) Differences between biopsy- or specimenrelated Lauren and World Health Organization classification in gastric cancer. World J Surg 26(2): 137-140

Folstein MF, Folstein SE, McHugh PR (1975) 'Mini-mental state'. A practical method for grading the cognitive state of patients for the clinician. J Psychiatr Res 12(3): 189-198

Hamilton SR, Aaltonen LA (eds) (2000) World Health Organization Classification of Tumours. Pathology and Genetics of Tumours of the Digestive System. IARC Press: Lyon

Huang XE, Tajima K, Hamajima N, Kodera Y, Yamamura Y, Xiang J, Tominaga S, Tokudome S (2000) Effects of dietary, drinking, and smoking habits on the prognosis of gastric cancer. Nutr cancer 38(1): 30-36

International Agency for Research on Cancer, International Association of Cancer Registries (2007) Cancer Incidence in Five Continents. Vol. IX. International Agency for Research on Cancer: Lyon, France

John RM, Ross H (2010) Economic value of disability-adjusted life years lost to cancers: 2008. J Clin Oncol 28(15s): suppl 1561

Ladeiras-Lopes R, Pereira AK, Nogueira A, Pinheiro-Torres T, Pinto I, Santos-Pereira R, Lunet N (2008) Smoking and gastric cancer: systematic review and meta-analysis of cohort studies. Cancer Causes Control 19(7): 689-701

Lopes C. (2000) Reproducibility and validation of a semi-quantitative foodfrequency questionnaire. Diet and acute myocardial infarction: a population-based case-control study. $\mathrm{PhD}$ Thesis [in Portuguese]. University of Porto, Porto

Lopes C, Aro A, Azevedo A, Ramos E, Barros H (2007) Intake and adipose tissue composition of fatty acids and risk of myocardial infarction in a male Portuguese community sample. J Am Diet Assoc 107(2): 276-286 
Lopes C, Oliveira A, Santos AC, Ramos E, Gaio AR, Severo M, Barros H (2006) Consumo alimentar no Porto. Faculdade de Medicina do Porto: Porto

Lunet N (2011) Helicobacter pylori infection in a region with high risk of gastric cancer [in Portuguese]. Arq Med 25(6): 213-217

Lunet N, Lacerda-Vieira A, Barros H (2005) Fruit and vegetables consumption and gastric cancer: a systematic review and meta-analysis of cohort studies. Nutr Cancer 53(1): 1-10

Lunet N, Pina F, Barros H (2004) Regional trends in Portuguese gastric cancer mortality (1984-1999). Eur J Cancer Prev 13(4): 271-275

Lunet N, Valbuena C, Carneiro F, Lopes C, Barros H (2006) Antioxidant vitamins and risk of gastric cancer: a case-control study in Portugal. Nutr Cancer 55(1): 71-77

Lunet N, Valbuena C, Vieira AL, Lopes C, David L, Carneiro F, Barros H (2007) Fruit and vegetable consumption and gastric cancer by location and histological type: case-control and meta-analysis. Eur J Cancer Prev 16(4): 312-327

Murden RA, McRae TD, Kaner S, Bucknam ME (1991) Mini-Mental State exam scores vary with education in blacks and whites. J Am Geriatr Soc 39(2): 149-155

Pacheco-Figueiredo L, Antunes L, Bento MJ, Lunet N (2011) Health-related behaviours in the EpiPorto study: cancer survivors vs participants with no cancer history. Eur J Cancer Prev 20(4): 348-354

Palli D, Bianchi S, Cipriani F, Duca P, Amorosi A, Avellini C, Russo A, Saragoni A, Todde P, Valdes E, Vindigni C, Blot WJ, Fraumeni Jr JF, Buiatti E (1991) Reproducibility of histologic classification of gastric cancer. Br J Cancer 63(5): 765-768

Palli D, Russo A, Saieva C, Salvini S, Amorosi A, Decarli A (2000) Dietary and familial determinants of 10-year survival among patients with gastric carcinoma. Cancer 89(6): 1205-1213
Patterson RE, Neuhouser ML, Hedderson MM, Schwartz SM, Standish LJ, Bowen DJ (2003) Changes in diet, physical activity, and supplement use among adults diagnosed with cancer. J Am Diet Assoc 103(3): 323-328

Peleteiro B, Lunet N, Barros R, La Vecchia C, Barros H (2010) Factors contributing to the underestimation of Helicobacter pylori-associated gastric cancer risk in a high-prevalence population. Cancer Causes Control 21(8): 1257-1264

Peleteiro B, Lunet N, Wen X, Afonso LP, Mendes N, Barros R, Carneiro F, Almeida R, Barros H (2011) Association between enviromental factors and CDX2 expression in gastric cancer patients. Eur J Cancer Prev; e-pub ahead of print 12 December 2011; doi:10.1097/CEJ.0b013e32834eflaa

ROR-Sul (2010) Incidência, Sobrevivência e Mortalidade por Cancro na Região Sul de Portugal - ISM 2004|2005. Registo Oncológico Regional Sul: Lisboa

RORENO (2010) Análise de Sobrevivência, Principais Cancros da Região Norte, 2000/2001. Registo Oncológico Regional do Norte: Porto

Verdecchia A, Francisci S, Brenner H, Gatta G, Micheli A, Mangone L, Kunkler I (2007) Recent cancer survival in Europe: a 2000-02 period analysis of EUROCARE-4 data. Lancet Oncol 8(9): 784-796

Willett W (1998) Nutr Epidemiol. 2nd edn. Oxford University Press: New York

World Cancer Research Fund \& American Institute for Cancer Research (2007) Food, Nutrition, Physical Activity and the Prevention of Cancer: a Global Perspective. IARC: Washington, DC

World Health Organization (1999) Definition, Diagnosis and Classification of Diabetes Mellitus and its Complications Part I: Diagnosis and Classification of Diabetes Mellitus. WHO: Geneva

This work is published under the standard license to publish agreement. After 12 months the work will become freely available and the license terms will switch to a Creative Commons Attribution-NonCommercial-Share Alike 3.0 Unported License. 